\title{
XIV. On some of the phænomena and laws of action of voltaic electricity, and on the construction of voltaic batteries
}

\section{Christopher Binks}

To cite this article: Christopher Binks (1837) XIV. On some of the phænomena and laws of action of voltaic electricity, and on the construction of voltaic batteries, Philosophical Magazine Series 3, 11:64-65, 68-89, DOI: 10.1080/14786443708649232

To link to this article: http://dx.doi.org/10.1080/14786443708649232

曲 Published online: 17 Jun 2009.

Submit your article to this journal $₫$

Џ Article views: 3

Q View related articles $\longleftarrow$ 
On the subject of the distinction between the Babel of the book of Genesis and the Babylon of Nebuchadnezzar, I have, in eonclusion, to adduce the authority of Diodorus Siculus, who informs us that, at the time of the conquest of Babylonia by the Assyrians under Ninus, Babylon itself was not in existence, although the country contained several other cities of importance*. This statement is entirely corroborative of the conclusion drawn from the various other authorities already cited by me, namely, that the Babylon which was known to the prophets, and which existed in the times of the writers of profane history, was a totally distinct city from, and one of a far more recent date than the Babel which was erected in the plain of Shinar previously to the dispersion of mankind.

I am, Gentlemen, your most cbedient servant,

Leipzig, March 23rd, 1837.

Charles T. Beke.

XIV. On some of the Phonomena and Laws of Action of Voltaic Electricity, and on the Construction of Voltaic Batteries. By Christopher Binks. Addressed to J. Frederic Daniell, Esq., F.R.S., Professor of Chemistry in King's College, London. $\uparrow$

\section{Dear Sir,}

T $\mathrm{N}$ your letter addressed to Dr. Faradaył, describing your 1 constant voltaic battery, you speak of seeking to reduce the zinc to a minimum comparatively with the surface of copper employed in the same mass of electrolyte; but it does not seem to have been your intention to determine precisely what was the proper relative proportion of the two metals. Subsequently to this remark in your letter, Mr. Mullins $\S$ has expressed his belief that the surface of zinc ordinarily brought into action in such combinations is much greater than is needed: but neither has he stated the precise results of experiment upon this point.

In the same communication, and in allusion to his new battery, Mr. Mullins speaks of his having discovered the existence of a new principle of action in voltaic combinations. He remarks, "In this battery the power is immense in proportion

"Admodum tamen probabile videri, continentem quondam magis versus austrum procurrisse, partemque ejus non exiguam procedente tempore aquis esse submersam, non dissimulaverim." Comment. Socict. Beg. Scient. Gotting. tom. xiii. Cl. Hist. p. 138. See also an abstract of the treatise printed in his Historische Werhe, vol iii. p. 337, Göttingen, 1821.

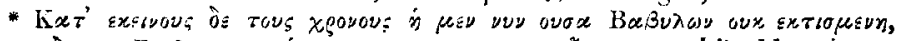

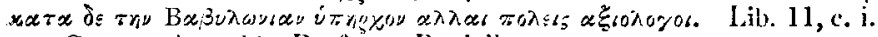

+ Comnunicated by Professor Daniell.

t Philosophical Transa tious, 1\$36, \$ Phil. Mag. for Oct., 1836. p. 285. 
to the quantity of metals used, and arises, I conceive, from the application of a principle which I believe is quite novel in the construction of voltaic batteries, namely, that of diminishing the metallic surfaces as the fluid in its onward passage accumulates; thus acquiring increased force in proportion to the smallness of the substance to which it is restricted." It was in the absence of the information that would have been derived from the promised communication from Mr. Mullins, or of precise information from any other source, that the following experiments were begun, having for their immediate object to determine what proportions should be preserved between the zinc and copper in any voltaic combination, and to trace the existence and nature of the principle of action alluded to in the above extract from the paper of Mr. Mullins.

Before the invention of your constant voltaic battery we possessed no instrument upon whose regularity of action we could depend, for either the establishing (by even an approximation to the truth) or the demonstrating of many of the laws of voltaic electricity. The battery of Wollaston, or modifications of it, either as an elementary or a compound one, had generally been employed in such investigations. But you have shown that there is an uncertainty and variableness in its operation, of so great an amount as should surely preclude its employment in experiments intended to decide upon the fundamental laws of the science.

It is, perhaps, to this circumstance mainly, or as much so as to that of our possessing no common standards of comparison in the majority of instances, that we owe the confiicting statements of the fundamental laws of the phenomena of galvanism which pervade the various treatises upon it. Of such conflicting statements we have one recent instance, among very many, in which the previously admitted law of the conductibility of wires of different lengths is called in question by E. Lenz ${ }^{*}$, whe substitutes in its place another law, of which the expression is, that "their conductibilities are in an inverse ratio to their lengths," in contradiction to that formerly held of their conducting power being "inversely as the square root of their lengths." I would submit that many other such laws are not yet decided, since it has not been shown generally in what way provision was made to guard against the irregular operation of the exciting battery employed, or that experimenters generally were aware that such irregularities prevailed, or at least, prevailed to so great an extent as has now been shown.

\footnotetext{
* Srientifie Memoirs, fart is p. 300. [See tiso p. $1 \mathrm{i}$ of the present Number.-Eurt]
} 
Let a sheet of common rolled zinc, carefully selected for its apparent uniformity of surface and thickness, be amalgamated in such a way as to secure the greatest uniformity in the distribution of the mercury over its surface. Let plates be cut from this sheet, exactly of the same size, and then associated with corresponding copper plates; and however well this may have been done, and however exactly alike the plates and every attendant circumstance may be, it will be found that no two of the couples will give the sane results in the same time, when arranged as simple galvanic circles and acted on by acids in the usual way. Whilst one zinc plate will lose 10 grains in a certain time, another compared with it and apparently exactly similar will lose perhaps only 6 grains, or, on the other hand, as much as 15 grains. Out of innumerable instances I have never been able to select two exactly alike, and in the closest approach to perfect similarity in the amount of action of any two which I have found there has still been between them a difference of $\frac{1}{2}$ th of the whole amount.

Again, any one plate, associated with a copper plate as a simple circle, wil! lose less the first time of its immersion than during the second, of which the following is one taken out of many such examples:

A plate of analgamated zinc, arranged with copper as a simple voltaic circle, and immersed (the acid being each time renewed) during periods of 30 minutes each :

Table No. 1.

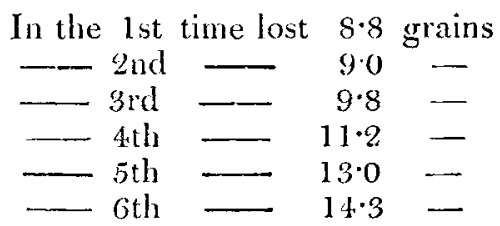

And when at the end of these the plate was amalgamated afresh and reimmersed, the action was reduced below its first amount, namely, to 6.7 grains in the 30 minutes.

'These sources of error, in cases where such elements are used, are independent of many others well known to experimenters, such, for instance, as accidental differences in the distance of the plates from one another, and the varying conditions of their surfaces.

Again, the common rolled zinc of the shops is very impure, and before undertaking investigations of phænomena in which comparisons of effects with the quantities of zinc consumed and hydrogen evolved are needed, the proper equivalent of the zinc actually employed must be determined.

In the midst of so niany sources of error, against which the 
utmost care can scarcely provide, it is but to be expected, so long as the same materials are used, that the greatest contrariety of opinion will exist on points apparently so easy to determine. A method of avoiding those errors which have their origin in the irregularity of the mutual action of the acid and zinc will be subnitted to you towards the end of my letter.

In order to avoid a too frequent recurrence to description in the course of this paper, I will, at this point, state generally some of the precautions (beyond the common and more obvious ones) that were taken to ensure accuracy in the results of the experiments.

The magnetic needle was never resorted to as a measurer of the amount of action or of the quantity of electricity developed; but this was estimated by what appears to me to be the more certain, though infinitely more laborious method, of finding, by the balance, the equivalent of zinc expended, or by actually measuring the volume of the evolved hydrogen. In no instance was the one calculated merely from the volume or weight of the other. In general both the balance and the meter were employed, whatever the number of the series in any experiment to be examined, and the number amounted in some cases to as many as fifty. I had anticipated that some curious results would appear from this mode of testing the phænomena, and have not been altogether disappointed. Again, when plates of amalgamated zinc were used in comparative experiments, in which equal ones, or differing by a certain ratio, were wanted, these comparative values were not estimated by the mere measure of their surfaces, but, by actually finding the amount of action upon them in a given time, by previous immersion in acid of a kind similar to that intended to be used; for an equality in the extent of surface does not ensure an equality of voltaic action, nor does that action increase in the same ratio as the surface may be increased, as has hitherto been believed. Again, the zinc employed throughout these experiments was always of the same quality, indeed was cut from the same sheet, and its equivalent cletermined, with hydrogen as unity, and found to be 34.5 . And in order, as far as possible, to reduce the number of the conditions involved in these experiments and requiring to be attended to and estimated, one of such was entirely avoided, viz. that of rariation in the distance between the two elementary plates. Whether used in independent or comparative experiments the mass of fluid interposed between the zinc and copper plates was invariably equal to one inch. The acid employed was the diluted sulphuric, and in those proportions which have become standard ones, through their having been used as such by yourself and Dr. Faraday. It is, perhaps, almost needless to remark that in any case where local 
action was discovered to have taken place it was either properly allowed for, the defective plate dismissed, or the experiment wholly repeated, and that where comparative estinates were made of the evolved gas or gasses, the proper corrections were made for temperature and pressure.

\section{First Investigation. Part I.}

'To determine the relative proportions of the zinc and copper needed to induce the maximum efrect in the action of any simple voltaic circle.

1st. To determine the influence and its extent of increasing the surface of the copper plate beyond that of the zinc.

Experiments. - A plate of amalgamated zinc, measuring square inches on each face, was associated successively with plates of copper, first of an equal size to the zinc and afterwards of a greater size, and gradually increasing in the ratio of the subjoined table. The times of immersion were each 30 minutes; the acid, a mixture of $4 \frac{1}{2}$ sulphuric (by measure) and 100 parts water, and at the end of each time the acid was renewed and the plate rinsed in clean water and weighed, when

(Table No. 2.)

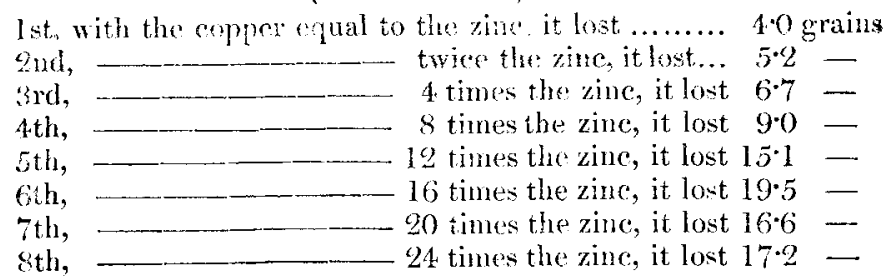

But throughout these experiments the same zinc plate was subjected to the action of the acid, and that extending through eight. periods of thirty minutes each, or through four hours. And it has been shown above in table No. 1 that a plate of zinc so placed loses more in the second time of immersion than during the first. Accordingly, to protect this examination from such a source of error, another plate with the copper equal to it was employed simultaneously and under like conditions, and was weighed at the end of the same times, when it was found to have lost in

(Table No. 3.)

1 st time, loss $=4.3$ grains $=0$

2nd time, loss $=4.3$ grains $=.0$

3rd time, loss $=4 \cdot 4$ grains $=\cdot 1$

4 th time, loss $=4 \cdot 6$ grains $=9$

5th time, loss $=4 \cdot 9$ grains $=\cdot 6$

6 th time, loss $=5.3$ grains $=1.0$

In progressive increase after the first immersion.

7 th time, loss $=5.9$ grains $=1.6$

8th time, loss $=6.7$ grains $=215$ 
which increase of action (reckoning from the third result) being deducted from the results of the corresponding periods in the former table, will leave that table to show the influence merely of the increased size of the copper plates, wtich is the point sought for. 'Therefore the table so corrected stands thus:

Table No. 4. corrected (from No. 2).

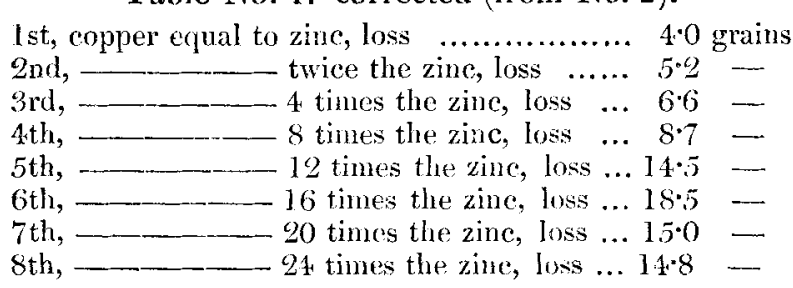

From which it appears that the greatest amount of action between the zinc and the acid is induced when the copper plate is 16 times larger than the zinc.

But in order further to test the accuracy of these results eight distinct zinc plates were selected, as nearly as possible alike, and the experiments repeated with the aid of a fresh zinc plate during each time, when the results were exactly the same as those exhibited in the corrected table No. 4.

This table, then, shows the proportion of the copper by which the greatest effect is produced under the then existing conditions of the atrangement. But it does not show us what is the absolute amount of power gained by using this proportion in preference to plates of an equal or of any other size; neither does it show whether the law it establishes will hold good under varying conditions of the action of the arrangement; whether, for instance, if its energy be increased or diminished, it will still require, to produce the utmost absolute effect, that the copper should be maintained of a size 16 times greater than the zinc.

To determine the former of these points let the result obtained by the plates of equal surface in zinc and copper (which we have in the first line of the above table No. 4) be taken as unity, and the other results reduced by it, when the table will stand thus:

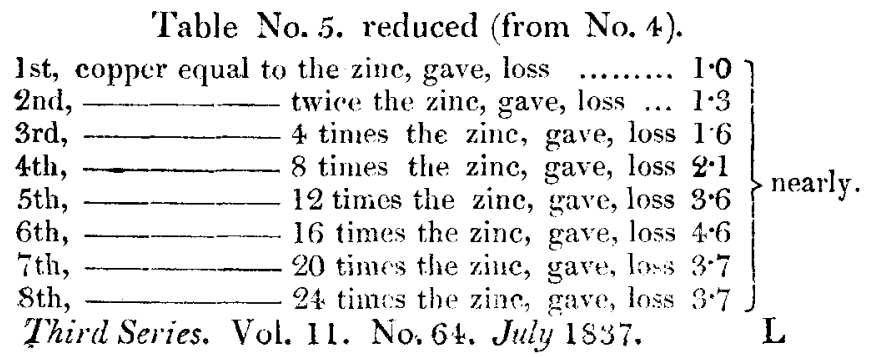




\section{Mr. Binks on the Lawes of Action of Voltaic Electricity,}

By which it is made apparent that (compared with equal plates) the effectiveness of any simple voltaic circle is increased about $4 \frac{1}{2}$ times, by having the surface of copper 16 times greater than the zinc.

But these results may not follow from the operation of an invariable law, but of one peculiar to the prevailing conditions of the arrangrements herein employed; as the activity of its action may evolve as much hydrogen as needs so large a surface to permit its formation with the greatest facility. But let the activity of the generating agents be lessened, and will it then need a surface equal to 16 , comparatively, to induce the greatest effect? Now this rapidity of action may be lessened by either removing the elementary plates further apart, or by more largely diluting the exciting acid. And to deternine the infuence of such changes, first, the plates were separated from the distance of one inch to that of two inches, and the experiments, with coppers of various surfaces, repeated, when, although less zinc was expended in the aggregate during an equal time, yet the greatest loss in any given period occurred when the copper was 16 times larger than the zinc.

The plates being restored to their usual distances from one another, the experiments were repeated twice, with acid solutions, formed, first, by the mixture of $2 \frac{1}{4}$ parts acid and 100 water, and, secondly, of 9 parts acid and 100 water, when the results were so nearly the same as those registered in the above table, as to indicate, without doubt, the operation in each instance of the same law, and to make it unquestionable that it was general, within at least the range of those circumstances here brought inco operation. For though, in the one case, the quantity of action was less and in the other more than in the standard tables, yet the maximum effect, in the respective sets of trials, was always exhibited when the copper was 16 times greater than the zinc.

An important poiut of inquiry now presents itself to be decided, namely, whether it is by the extension of surface merely that this advantage is gained, or whether it be due to the greater mass of conducting copser thus brought into action, or to the united influence of both. Experiments were made to determine this point, from which this one may be selected :

An amalgamated zinc plate, measuring 4 square inches, was employed in the first instance, along with a sheet of thin copper, weighing a few ounces, and having a surface of 16 square inches, when the result in zinc lost was $6 \frac{9}{10}$ grains. Then the same zinc plate was connected with a solid prism of copper, of the same external dimensions as the sheet just used, but weighing about two pounds, when the zinc lost, during an equal time, 
7.2 grs. And when the solid mass was extended in its surface, or (which is the same thing) when two pounds' weight of sheet copper was joined with the same zinc plate, the amount of action upon it was found to be increased from $7 \cdot 2$ to 16.5 grains; the former loss resulting from the influence of a surface equal to 16 square inches, and the latter from that of about 170 square inches; showing distinctly that it is to extended surface only that this effect is to be ascribed, and that it is in no respect due to the influence of the better conducting power of the metal as a mass.

It is remarkable that in this law of action to which the foregoing experiments have led me, but which is widely different from any I had anticipated, we have an exact correspondence with the specific gravities of the two gases involved in its operation. The specific gravities of oxygen and hydrogen are as 16 to 1 ; and it is when this proportion between the two surfaces, upon which they respectively appear, is preserved, that any voltaic combination seems to be placed in the best position for the exercise of its full power. This correspondence may therefore be presumed to be something more than a mere coincidence.

' $T$ wo other points, bearing more immediately upon the application of these principles to the construction of the battery, remain to be decided. In the preceding experiments the copper plate did not extend over, nor was it placed opposite to, both surfaces of the generating zinc, as in the arrangement adopted by Wollaston; but was placed opposite one face only of it. It therefore occurs, as a part of the inquiry, whether the action upon the zinc took place upon or belonged to that surface only which was next to the conducting copper one, or whether it was due to an influence extending over the whole surface of the zinc immersed: whether, if another copper plate, of the determined dimensions, were placed over against the other surface of the zinc, we should gain a firther and double accession of power?

Experiment. 1st. A zinc plate, with copper equal to 16, placed on one side only, lost $12.0 \mathrm{grains}$. 2nd. The same, with two copper plates, one on each side, and presenting, in full, a surface comparatively of 32, , lost $12 \cdot 3$ grains in an equal time.

There is, therefore, nothing to be gained by apportioning buth surfaces of the generating plate, provided the copper plate on the one side be in the full proportion.

Again: is the influence of the copper plate due to the exercise of one, or of both its surfaces? Do they both operate or only that one opposite the zinc? 
76 Mr. Binks on the Laws of Action of Voltaic Electricity,

Experiment. 1st. A copper plate, clean on both its sides, was first put in operation; when its associated zinc plate lost $12 \cdot 2$ grs. gud. One side of the copper plate was now covered with wax and the commected zinc plate then lost 10.5 grains; sbowing, as you have remarked before*, that the outer surface is, to a slight extent, engaged in the operation; but not so importantly as to make it of inuch regard in the construction of voltaic batteries.

\section{First Investigation. Part II.}

To determine the influence and its extent, of increasing the size of the zinc plate beyond that of the copper one.

In some of the galvanic batteries recently constructed the form is such that each successive couple is greater or smaller by a certain ratio than its adjoining one; and the arrangement of such a combination may be, either that a zinc plate is operating along with a larger copper plate; or that the zinc plate is the superior in size compared with the copper one immersed with it and operating in the same mass of liquid. Besides this, it is a matter of common remark, that the power of such arrangements is augmented by the employment of zinc plates the larger of the two.

Having already determined the kind and amount of influence exercised by copper plates of various comparative sizes, it follows to determine in what way the zinc or generating surfaces will operate when made the greater of the two; the ultimate object of the inquiry being to test the alleged superiority of those forms of voltaic batteries which permit of such an arraugement being brought into action.

The experiments were conducted in a manner similar to the preceding ones, except that, in as much as the zinc plates here used were too large to admit of their being weighed with sufficient nicety, the amount of action was estimated, not by the loss of metal, but by the measure of evolved hydrogen.

First the two plates were of equal size, then the zinc was increased, the original copper plate being used throughout.

\section{Table No. 6.}

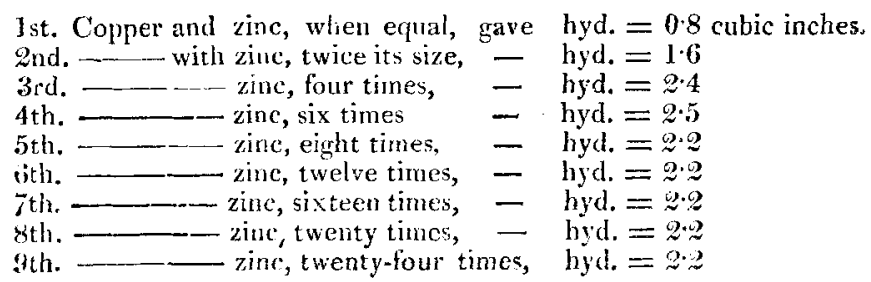

* Philosophical Transactions, 1836, p 113,116. 
Then, taking the results of equal plates (or the first line of the above) as unity, this table reduced stands thus:

Table No. 7. (No. 6. reduced.)

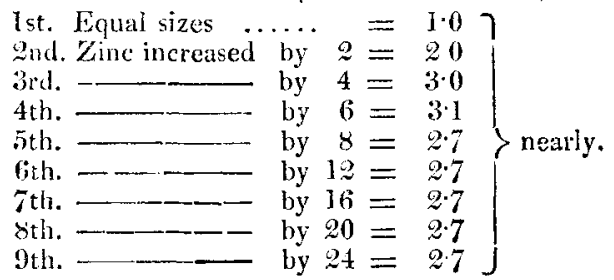

Showing by the first (No. 6.) that the greatest effect follows upon the employment of a zinc plate six or seven times larger than the copper; and by the second table (No. 7.) that the absolute amount of action gained (when that is at its maximum) is about three times beyond that produced when the plates are equal.

To sum up the results brought out by the foregoing investigation, it appears that both the zinc and copper phiates exercise a definite influence when either is made the larger in any voltaic arrangement; but that that influence is different in degree in each case; that when the zinc is the larger, its full effect is obtained when it is about seven times the greater, and the absolute amount of that effect is three compared with equal plates as one: but that when the copper is the greater in the arrangement, then its full effect is not reached till it measure sixteen times greater than the zinc, and the total absolute amount gained, over equal plates, is four and a half.

Having ascertained these facts, I now proceeded to trace their influence in compound arrangements, as well as in the simple elementary ones to which the experiments had hitherto been restricted. Accordingly I prepared three batteries, consisting of a series of ten couples each.

The first (A) had the zinc and copper plates of equal size, and each plate presented a surface of four square inches to the action of the acid.

The second (B) had zinc plates of the same dimensions as those of A, but were connected to copper ones sixteen times larger, that is, the zinc were each four and the copper sixtyfour square inches in surface.

The third battery was furnished with copper plates the same size as those in $\mathrm{A}$; but the zinc ones were seven times larger, that is, the copper ones were four square inches each, and the zinc ones twenty-eight.

These batteries being each excited by an acid mixture of the same strength, and their action continued throngh equal 


\section{Mr. Binks on the Lawes of Action of Voltaic Electricity,}

times, gave the following results, as indicated by an interposed voltameter:

$A$, in 30 minutes gave in mixed gases 1.2 cubic inch. $B$, in do. do. 6.8 cubic inches.

$\mathrm{C}$, in do. do. $\$ 5$

Demonstrating that the laws just proved to operate in the case of single arrangements, operate also in that of compound ones. But the advantages gained in $\mathrm{B}$ and $\mathrm{C}$ are greater even than had been anticipated by those laws, a circumstance which is explained in a subsequent investigation (No. 3.), when it will be proved that the above results are in exact accordance with those found to obtain in the case of the single arrangements already treated of.

There is one fact brought ont by the above experiments to which I should wish to attract your attention, merely premising, that inasmuch as the coincidence between it and some other facts, which I suspect may be detected, may or may not be purely of an accidental character, I should wish to be understood as attaching no importance to it beyond that which would make me bear it in mind till our further acquaintance with the origin and operations of this still mysterious agent may contribute to its proper explanation. The fact $I$ allude to is this: in 'Table, No. 6, it is shown that it is when the surface of the zinc plate becomes equal to about seven (the copper being one) that the full voltaic effect is produced: why is $i t$, that the action regularly increases in amount till the respective surfaces reach this relative proportion, and that it then ceases to be augmented under any further addition whatever?

Second Investigation.

An inquiry into the comparative action of surfaces of different extent; that is, whether the action of any voltaic combination increases directly as the surface increases, or in some other ratio.

Depending upon the accuracy of that law (which has been generally admitted), that if the surfaces of the plates be increased, the resulting action will be increased in the same ratio, I had been led into some strangely anomalous results in my experiments, which could be accounted for only on the supposition that this law might possibly be incorrect. I had found litule reason to dispute its accuracy when the examinations were restricted to plates varying from one square inch to four ; but when carried beyond these sizes, its fallacy became strikingly apparent.

To examine into this, I prepared several simple arange- 
ments composed of zinc and copper in the proportions of one to sixteen. The sizes of the zinc plates are stated in the subjoined table. At the end of each time of immersion the acid mixture was renewed, \&c.; when it appeared that,

\section{(Table No. 8.)}

Jst. A zinc plate measuring one square inch, lost (in $30 \mathrm{~min}$.) $\tilde{5} 0 \mathrm{grs}$.

2nd. A zinc do.

two - inches, lnst (do.) $9 \cdot 9$

3rd. A zinc do. - four - - Jost ( - ) 19.0

4th. A zinc do. - eight - - lost ( - )

5th. A zine do. - - sizteen - lost ( - ) 400

Now, had the formerly admitted law of increase been true, we should have had the last plate in the table exhibiting a result of action equal to sixteen times greater than the first one; since its surface is sixteen times larger. But the first loses five grains, and the last 40 ; whereas, had this law been correct, it should have lost 80 grains, or $5 \times 16$; but the result found by actual experiment is only one half or $40 \mathrm{grs}$.

But was this result the effect of any peculiar concitions attending the experiments? I varied the form of the experiments in every possible way, but with still the same general results. For instance, the zinc and copper plates were connected by wires of thicknesses proportional to their theoretical values; when the results were the same: or the conducting wires were made to extend around the whole outer edge of the generating plates and thence to the copper ones, or one entire side of the zinc was covered by a conducting plate of copper, (itself and the joinings, both in this and the last case, being carefully protected from the acid by varnish, yet by every modification the same general results were brought out. The increase, therefore, is not as the surface, but in some other ratio yet to be determined.

\section{Third Investigation.}

To determine the kind of influence exercised by single voltaic arrangenents, one upon another, when used in connection, whether they be of equat or of unequal sizes.

It is but to be expected, à priori, that arrangements so situated and connected as in the following experiments, will exhibit the operation of laws, not of an arbitrary but of a definite and unchanging lind. The great discovery of Faraday leads necessarily to this expectation; and every correct experiment will unquestionably confirm his law, and exhibit its extended influence. 'These experiments, however, have no pretension beyond that of reaching to such a degree of accuracy as shall be subservient to their avowed object: such a degree of minuteness only is aimed at as shall prove of practical value to the ultimate object of the whole inquiry, namely, the construction of the battery. 
s) Mr. Binks on the Laws of Action of Voltaic Electricity,

Let a single voltaic arrangement be immersed in acid of a certain strength, and during a certain length of time, and its voltaic action determined by the quantity of zinc lost, or of hydrogen evolved. Let another such arrangement (either of equal or of unequal size) be tested in the same manner; and then (having thus determined the amount of action peculiar to each when acting separately) let them be connected as a compound arrangement; that is, let the zinc of each one arrangement be joined by a wire to the copper of the other, and then the amount of action determined when thus operating upon one another.

'These experiments were so contrived that the distance between the elementary zinc and copper plates, in any arrangement, was always the same; and also that the wires connecting them (whether when used separately or in connection) were always of the same length, in order to avoid those differences in the results which would have arisen had these precautions not been strictly observed.

I shall select the following as a preliminary example of such a mode of analysis :

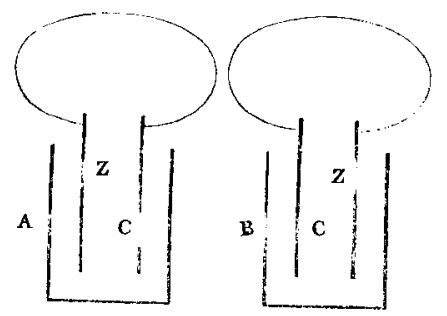

$\Lambda$ plate of zinc (in A) and a plate of copper of the same size, joined together as a simple circle, were immersed in an acid mixture during 30 minutes, and gave off hydrogen equal to $3 \frac{2}{10}$ cubic inches. Another such arrangement (in $\mathrm{B}$ ), but of larger size, was treated in the same way and yielded 16 cubic inches of hydrogen.

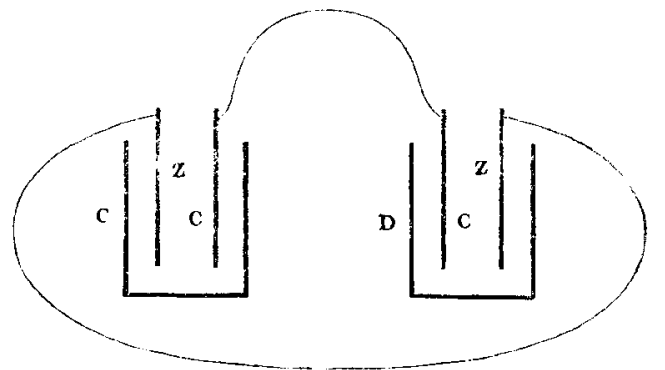

these same arrangements were now connected as repre- 
sented in $\mathbf{C}$ and $\mathrm{D}$; and (every circumstance being preserved the same as before) $C$ yielded $4 \cdot 4$ cubic inches of hydrogen, and $\mathrm{D}$ precisely the same, viz. $4 \cdot 4$ cubic inches.

When separated.

A was equal to $3.2 \mathrm{cub}$. in. B

Total ... $\overline{19 \cdot 4}$
When joined.

C was equal to $4 \cdot 4$ cub. in. D _- $4 \cdot 4$ cub. in.

$$
\text { Total ... }
$$

From which it appears that when mutually operating the action is distributed equally over both; but that its total amount is reduced by about one half from that which took place when the arrangements were distinct.

This example will serve to indicate the kind and object of the following experiments, with which I will now proceed systematically.

A. To determine the mutual influence exercised by arrangements when they are of the same size.

I prepared forty-eight arrangements, formed each of plates of zinc and copper of the same size, each plate measuring four square inches. I first took a number of these arrangements, and immersed them separately, and found, by an average, the loss that each sustained in a certain length of time. This average I found to be 5.7 grains of zinc expended; and it is accordingly placed first in the annexed table, as a standard of comparison.

I now took two of these arrangements and connected them as in the above example, and found the result of their action. Then four such were connected, and the results ascertained in the same way, as were also the results of combinations of $8,16,32$, \&c. as shown in the table.

$$
\text { Table No. } 9 .
$$

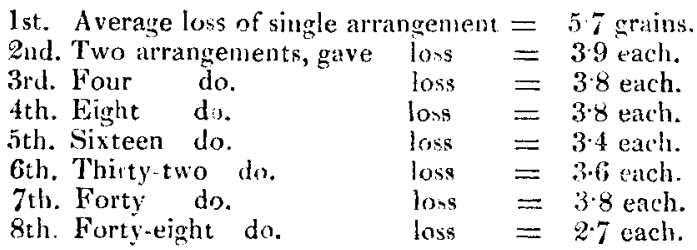

Now it will be seen by this table that the amount of action in combined arrangements is less than the action in single cnes. For instance, the action of two such joined is about one third less than takes place when they are used separately. This was unexpected; but not more so than some other results that follow. I have had the greatest difficulty in deciding upon the precise amount of the difference between the action of

Third Series. Vol, 11. No. 65. Suppl. Suly 1837. 


\section{Mr. Binks on the Lares of Action of l'oltaic Electricity,}

single and double arrangements. Sometimes the action in the latter case has been reduced one half, sometimes one fifth, but more frequently one third ; and the cause of this variableness I have been wholly unable to detect. But this uncertainty does not attach to those cases in which more than two arrangements are operating, as will be made evident as these experiments proceed. It will also he seen by this table, that although the number of the series was extended to 48 , yet the action in any one of the combined series never became equal in amount to that which took place when they were used separately.

B. To determine the mutual influence exercised by arrange. ments when they are of different sizes compared with one another.

As I have already given an example of this kind of examination above, I need not further explain the manner of conducting it, but will exhibit the results at one view in the subjoined Table No. 10.

1st, Arrangements of equal size. When separate. When joined.

A gave hyd. ... $0 \cdot 8$ cubic inch. I gave hyd. ... 0.4 cubic inch.

$\mathrm{B}$ gave hyd. ... 0.8 -..

$B$ gave bid. ... $0 \cdot 4$

$$
\text { Total } \overline{1.6} \quad \text { 'Total } \overline{0.8}
$$

znd, With the arrangements differing in size in the proportion of 1 to 3 .

C gave hyd. ...24 cubic inch. (C gave hyd. ...24 cubic inches.

D gave hyd. ... 7.4 -

$D$ gave hyd.
Total $\frac{2 \cdot 4}{4 \cdot 8}$

3rd, With the arrangements differing in size in the proportion of 1 to 5 .

F gave hyd. ... $3 \cdot 2$ cubic inches. F gave hyd. .. $4 \cdot 4$ cubic inches.

$F$ gave hyd, $\ldots \frac{16.0}{19.2} \quad \longrightarrow \quad \begin{array}{r}F \text { gave hyd. } \ldots .4 .4 \\ \text { Total Total }\end{array}$

4th, With the arrangements differing in size in the proportion of 1 to 9 .

$G$ gave hyd. .. $1 \cdot 4$ cubic inches. (9 gave hyd. ... $2 \cdot 6$ culvic inches.

$H$ gave hyd. ... $12 \cdot 0 \quad-. .-\quad H$ gave hyd. ... $3 \cdot 6$

$$
\text { Total } 13.4 \quad \text { Total } \overline{6.2}
$$

5th, With the arraugements differing in the proportion of 1 to 16.

I gave hyd. .. 0.8 cubic inches. 1 gave hyd. ... 1.6 cubic inches,

$\begin{array}{llllll}K & \text { gave hid. } & \ldots & 12 \cdot 8 & & 2.8\end{array}$

$\begin{array}{lll}\text { Total } & 136 & \text { Tot:1 } \overline{4 \cdot 9}\end{array}$ 
It will be observed here that in the 4 th and 5 th instances, in which there was a great disparity between the sizes of the two arrangements, the results of their combined action were not divided equally between the two, but appeared greater in that vessel in which the greater zinc plate was acting. But when we come to those experiments in which the arrangements are fitted to copper plates in the relative proportion of 16 to $l$ of zinc, it will be seen that the results are different; that then in every instance the action is equally distributed through any combined series.

I now tried a combination of three arrangements, in which Table No. 11.

When seprarate. When joined.

A gave hyd. ... 2. cubic inches. A gave hyd. ... 344 cubic inches.

B gave hyd. ... 9. _..._. B gave hyd. ... 34

$\mathrm{C}$ gave hyd. ... 18. _... C Cave hid. ... 3.4

Total $\quad \overline{29}$ Total $\overline{10 \%}$

These experiments appear to be interesting in other respects than as they bear upon the object for which they were expressly made. But confining nyself to the immediate purpose I proceed to show:

C. The mutual influence of arrangements when they were equal in size compared with one another, but in which the elementary zinc and copper plates are in the proportion of 1 to 16.

Three arrangements were prepared exactly alike.

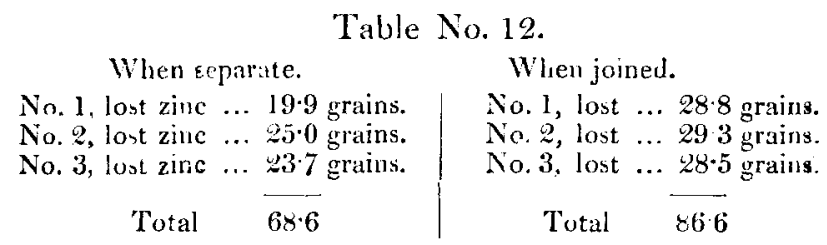

Showing by the results in A that when similar arrangements were connected with copper plates of the same size as the zinc, their combined action was remarkably reduced; but when the copper piates were in the proportion of the last experiment in $\mathrm{C}$, then, instead of a great reduction in the amount of their action when combined, compared with what it was when they were separate, we find that their action is as remarkably increased: for by Table, No. 9, (in which the copper and zitic plates are equal) we find a reduction of about one third to tuke place on combination, and in this last investigation, $C$, we find as remarkable an increase.

D. To detcrmine the influence exercised in those cases in II 2 
84 Mr. Binks on the Lates of Action of Voltaic Electricity,

which the elementary plates are in the proportions last observed (in C), but in which the arrangements themselves are unequal.

Three arrangements were employed.

\section{Table No. 13.}

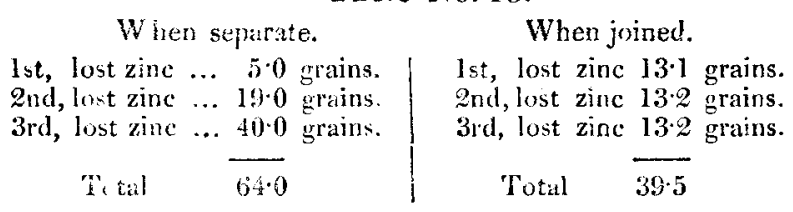

Showing a remarkable decrease in action (as has invariably occurred) to follow the employment of voltaic arrangements of unequal sizes when compared one with another in the same series.

I should wish it to be particularly remarked here, that in this last experiment (D) and in the one preceding it (C) the total surfaces of the metals in operation were exactly of the same dimension:

$\left.\begin{array}{l}\text { The zinc plates in } \mathrm{C} \text { measured each } 7 \text { square inches } \\ \text { The copper plates do. do. } 112 \text { square inches }\end{array}\right\}$ which

being untiplied by 3 (the number tseri) give zinc equal to 21 square inches, and copper equal to 326 square inches in the whole. And in D the 1st arrangement was composed of 1 square inch zinc and 16 copper; the 2 nd, of 4 square inches zine and 64 copper; the 3rd, of 16 square inches zinc and 256 copper, making a total, the same exactly as in C, namely, of 21 square inches of zinc, and 936 square inches of copper. And it has been shown that when these two sets of arrangements were put in operation, the one (C) lost $86^{\circ} 6$ grs., and the other (D) lost only 39.5 grs.

The conclusion to which these experiments obviously lead is this: that there is no advantage to be gained by using the elementary conbinations of any voltaic battery of an unequal size when compared with one another; but on the other hand, that such a form of battery is remarkably defective when compared with another, having an equal extent of metallic surface, but in which the elementary couples are of uniform size throughout the series.

'To verify the conclusion here advanced I prepared three small batteries, and tested their comparative efficacy by their power of decomposing water.

Each battery consisted of a combination of six elementary couples, and the total surface of zine in each battery was 63 square inches and of copper 1008 square inclies. 
The first, or A, had its elementary couples of equal size; each of its zinc plates measured $10 \frac{1}{2}$ square inches, and each of its copper ones 168 square inches.

The second, or B, had its couples of unequal sizes, as seen in this table.

1 st couple had zinc $=1$ square inch, and copper $=16$ square inches.

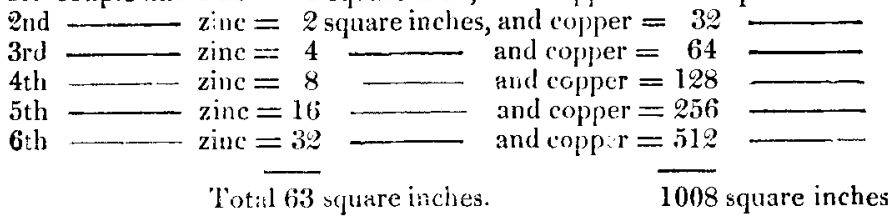

The third battery, or $\mathrm{C}$, had its couples also uncqual, but increasing from the frrst one by a different progression. I need only write out the dimensions of the zinc, each corresponding copper being sixteen times larger.

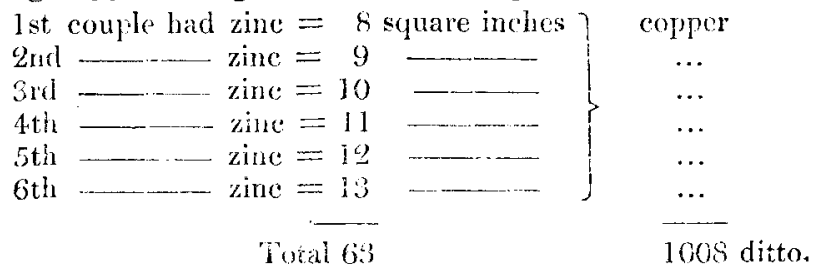

The electricity developed by each of these batteries was passed in succession through a voltameter holding acidulated water, during times of 30 minutes each; when

$A$ yielded of mixed gases, $1 \cdot 3$ cub. inch, $B$ yielded do. do. 0.7 cub. inch, $C$ yielded do. do. $1.1 \mathrm{cub}$. inch, results which verily the conclusion drawn from the preceding experiments, and which prove besicies that even when the difference in the sizes of the component circles of the battery is as trifling as in C, their inequality is attended too with a narked inferiority of action.

Since the above experiments were made I have contrived an apparatus by which such kinds of experiments, and many others of great importance to the science, may be conducted with the greatest possible precision and certainty. Its principle depends essentially on the substitution, in the place of amalgamated plates, of a fuid amalgam, formed by the union of 20 parts by weight of mercury and 1 of zinc. But as this paper has alleady exceeded any reasonable limits, I will not trespass on your patience with any description of its form or operation beyond that of merely stating that it appears to me to he admirably calculated for deciding many of the 
controverted points in the laws of this science; and one of such to which I shall attempt to apply it will be to determine the real relation that subsists between the deflexions of the magnetic needle and the quantity of zinc expended in producing those deflexions, or, which is the same thing, between the deflexions and the quantity of electricity which produces then.

\section{Fourth Investigation.}

Up to this siep in the inquiry I have restricted myself to the use of diluted sulphuric acid as the exciting agent. The foregoing facts, or, it may be, laws of action, have therefore been determined for this one condition only out of the many under which the electrical action may be developed. The phienomena attendant upon this mode of excitation are, primarily, the decomposition of the water, the combination of its oxygen with the zinc, and the liberation of its hydrogen as hydrogen, that is, in its gaseons state, upon the surface of the conducting metal. Now, in the results of the first investigation we perceive that there exists a coincidence between the relative bulks (compared with equal weights) of oxygen and hydrogen gases and the relative surfaces of the two metallic plates of any roltaic circle in which the maximum electrical effect takes place. This fict, which I speak of as a mere coincidence, should not be overlooked. It may indicate a priori that the same relative proportions in the two metals which have been determined for this one instance may be needed in every instance in which water is decomposed and its hydrogen liberated in the form of gas. But we have no reason to anticipate a priori that if any other substance than hydrogen be yielded at the conducting plate, we shall still, to produce the maximum effect, have to preserve the same proportions of the two metals as have been determined for that case. Suppose the operations within the cells of any battery to be so modified that, although water shall still be the substance decomposed, yet intead of the production of hyologen we have the deposition of metallic copper, or the reformation of water, or the formation of some other boly physically different from hydrogen as the results of the operations, what propostions of the two metals will then be needed to ensure the maximum effect? Such modifying agents are readily obtained. A proper mixture of the nitric and sulphuric acids with water will lead, not to the production of gaseous hydrogen, but to the formation of water and ammonia within the cells of the battery; and the solution of sulphate of copper to the deposition of metallic copper and the refornation of water. I will at this time examine but the latter of these two, and endeavour to determine 
what proportions should be observed between the two metals when the copper is immersed in a solution of its sulphate.

The experiments were conducted as in the first investigntion. The zinc was immersed in dilute sulphuric acid, formed of $4 \frac{1}{2}$ acid to 100 water, and confined in a membranous bag, the copper solution surrounding it.

The zinc plate measured 2 square inches; it, as well as the acid and solution, was renewed each time of immersion. The first copper plate was equal in size to the zinc, then the copper plates were used of larger sizes in succession, as seen in the table.

$$
\text { Table No. } 14 .
$$

Ist, zine with copper, equal, in 30 minutes lost... $6^{\circ} 0$ grains

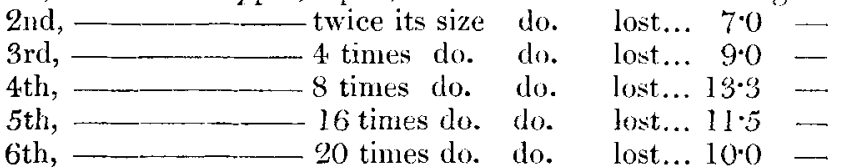

I am wholly unable to account for the deficiency in action observed in the fifth and sixth instances, when compared with the fourth, since the conditions of the experiments were in each instance precisely alike, save of course the size of the experimental copper plates.

This table, therefore, indicates that it is when the copper plate is about eight times larger than the zinc one, that the greatest effect ensues in the case in which sulphate of copper surrounds the conducting plate, and the voltaic action is accompanied by the deposition of metallic copper and the reformation of water.

These trials were varied twice; first by using a stronger acid solution to act upon the zinc; and secondly, by using merely water for the same purpose, when the results exhibited the operation of the same law, namely, that the maximum effect followed upon the employment of the copper plate about eight times larger than the zinc.

For rensons already sufficiently adverted to, I have confined my examinations to some of the cases nost commonly met with in the ordinary employment of the battery. But were this kind of examination extended into every case of voltaic action in which different bodies, that is, bodies physically different from one another, are the result of the operations wirhin the cells of the battery, I have no doubt that a specific and different proportion between the sizes of the two constituent metals would be found to be necded for each case, in order to obtain the maximum effect; and that the relations which would be thus discovered would be at once curious 
and of the utmost importance to the general theory of the science.

My own experiments have been extended to the examination of only two of such cases; namely, first to that in which sulphuric acid is the exciting agent, and gaseous hydrogen the product upon the surface of the conducting metal; and secondly, to that in which sulphuric acid (derived either from the dissolved sulphate, or from free acid previously added) is still the exciting agent, but in which metallic copper is the product appearing at the conducting plate; these two having been selected, from the highly distinctive character of their respective phænomena.

Recurring to the former of these investigations, I should wish, before concluding this paper, to attract your attention to a fact which has been invariably presented in their course, when the arrangement of any voltaic battery has been such that the whole of its evolved hydrogen could be collected, and the total quantity of zinc employed in its formation be also ascertained.

If a single voltaic arrangement be employed to generate hydrogen, an exact correspondence will be perceived between the quantity of zinc expended and the volume of hydrogen evolved, and their theoretical proportions as determined by calculation. 'The same regularity will be maintained whether plain or amalgamated plates of zinc be employed in the arrangement, and also whether single, or double, or treble arrangements, \&c., connected, be brought into operation with this view; up to a certain number of such, if the hydrogen and zinc be compared, there will be found to be a perfect agreement between their quantities and those anticipated by theory. But if the number of voltaic pairs be so many that the battery possesses energy enough to decompose water when submitted to it in the usual way, then this exact correspondence between the proportions of the hydrogen and the zinc will be no longer maintained; but it will be found that the total quantity of zinc expended will be greater, by about one third, than is needed to generate the quantity of hydrogen actually evolved.

As I intend to enter upon a more minute examination of this phænomenon, I will, at this moment, offer but a single example of it, which is sufficiently marked and accurate to indicate its real nature.

A small battery of 16 equal pairs, arranged as the couronne des tasses, was put in operation; and so combined that the hydrogen from each cell could be collected and each zinc plate 
weighed at the end of a certain time. Each vessel was found to contain as nearly as possible the same measure of hydrogen; and a like equality of action upon the zinc had taken place throughout the series.

The total quantity of hydrogen was $60^{\circ} 6$ cubic inches; the total quantity of zinc expended was 74.0 grains.

Now, I had previously determined that 34.5 grains of the zinc I employed were needed to produce an equivalent of hydrogen; and taking the weight of 100 cubic inches to be $2 \cdot 1318$ grains, we have the measure of an equivalent of hydrogen equal to $46: 9$ cubic inches. Therefore, the 74.0 grains of zinc here consumed should have yielded 100.5 cubic inches of the gas, but they actually yielded only $60^{\circ} 6$ cubic inches.

Whether or not a voltameter were interposed the results were similar : invariably the same want of correspondence appeared between the loss of the zinc and the volume of evolved gas and their relative quantities as found by theory; and the amount of this difference was always somewhat similar to that exhibited in the above experiment.

The operations within the cells of the battery admit of easy analysis, and this phænomenon also admits perhaps of an easy explanation; but the fact it seems to indicate, viz. that a certain portion (and that about one third of the whole) of the hydrogen subserves some purpose closely connected with the power of the battery to decompose water, appears to be of so much importance as to make it deserving of a more careful examination. I remain, dear Sir, Your obliged friend and pupil,

Newington, Edinburgh, March פ2, 1837.

C. BINKs.

XV. Proceedings of Learned Societies. IHOYAI. SOCIETY.

[Continued fron vol. x. p. 382.]

April 6.- A paper was in part read, entitled, "Further ObserArions; in a letter addressed to Michael Faraday, Esq., D.C.L. F.R.S., Fullerian Professor of Chemistry in the Royal Institution, \&c. \&c." By John Frederick Daniell, Esq., F.R.S., Professor of Chemistry in King's College, London.*

April 13.- The reading of Professor Daniell's paper was resumed and concluded.

In the course of an inquiry into the effects of changes of temperature upon vol taic action, the author was led to observe some curious

* Abstracts of Prof. Daniell's former papers have been given in Lond. and Edinb. Phil. Mag., vol. viii. p. 421 ; vol. ix. p. 376.

Third Series. Vol, 11. No.65, Supplement, July 1837. N 